\title{
Um passado ressignificado: considerações sobre engajamento social e performatividade neorrealista em Levantado do chão, de José Saramago \\ p. $29-37$
}

Mariana Sousa Dias ${ }^{1}$

\section{Resumo}

O presente artigo analisa a performatividade neorrealista do romance Levantado do chão, de José Saramago, pontuando sua importância para o engajamento social e para o desenvolvimento da literatura portuguesa da segunda metade do século XX.

Palavras-chaves: José Saramago. Levantado do chão. Neorrealismo.

\begin{abstract}
This article analyzes the neorealist performativity of the novel Levantado do chão, by José Saramago, focusing its importance for social engagement and the development of portuguese literature in the second half of the twentieth century.
\end{abstract}

Key words: José Saramago. Levantado do chão. Neorealism.

Levantado do chão (1980) foi escrito a partir de uma viagem de dois meses que Saramago empreendeu ao Alentejo, no ano de 1975, em busca de documentos e depoimentos sobre a região. A partir de suas impressões, o escritor re(a)presenta, no romance, os diversos relatos dos trabalhadores rurais, traçando os processos que desencadearam sucessivas mobilizações, greves e enfrentamentos, diante das injustiças estabelecidas durante anos pelo sistema latifundiário.

Os anos 30 e 40 do Século XX, em Portugal, foram marcados por uma série de problemáticas, como desemprego, fome e indigência. Politicamente, a ascensão do salazarismo instaura um forte aparelho censório como principal forma de inibição do processo de contestação que postula um claro direcionamento ideológico de subversão da ordem opressora. No campo literário, a contraposição do neorrealismo à arte pela arte, bem como a defesa de uma literatura comprometida com os problemas do país, são características notórias: sob as influências do materialismo dialético, o movimento buscou apresentar informações sobre a sociedade portuguesa, tornando-se uma importante voz de resistência ao regime. Assiste-se, assim, ao surgimento de uma escrita que não enfoca os grandes e tradicionalmente sacralizados herois da nação portuguesa, mas sim o retrato da dura realidade operária.

A partir de tais considerações, pode-se afirmar que as temáticas da miséria do povo e da exploração dos trabalhadores representam a tônica do neorrealismo português, juntamente à resistência ao regime ditatorial. O discurso (anti) épico de uma identidade nacional baseada na 
glória da pátria é subvertido, voltando-se para os problemas concretos da população.

Numa aproximação de tal olhar, Levantado do Chão ficcionaliza as memórias coletivas oriundas dos trabalhadores rurais alentejanos, às quais claramente se alinha o autor. Segundo Vitor Viçoso:

O romance neorrealista arquetípico [...] seria a fusão de uma interpretação sociológica das classes trabalhadoras (campesinato e operariado) e de uma idealização do outro social enquanto agente épico da revolução que viesse a atualizar o desejo ético-político do escritor. (VIÇOSO, 1999, p. 241)

Uma vez que o neorrealismo desenvolveuse entre finais da década de 30 e meados da década de 60 do século XX, evidentemente, Levantado do chão não pode ser considerado um romance da corrente. É preciso, entretanto, notar que alguns de seus elementos constitutivos - em especial o grupo social retratado -, dialogam claramente com tal estética. Mediante suas experiências, as personagens criados por José Saramago indicam a trajetória da tomada de consciência que resulta em momentos e meios adequados para que o povo pudesse reagir às forças opressoras: o traço mais evidente da interseção do romance com o neorrealismo está, desse modo, na evocação dos homens que outrora foram condenados à margem da sociedade, ou seja, numa retratação aos heróis desconhecidos da/pela nação.

Lembrar o passado e escrever sobre ele mostram-se como atividades complexas e nada inocentes. Utilizando-se de um aparato cuidadosamente instituído para justificar e obscurecer determinadas vozes, classes dominantes perpetuam o processo de apagamento, e a história, enquanto instância seletiva, não pode dar conta de todos os acontecimentos e pontos de vista.

A partir de tais premissas, um elemento fundamental no tocante à arbitrariedade do discurso histórico deve ser levantado: a diferenciação entre memória coletiva e história. Maurice Halbwachs aponta distanciamentos básicos entre tais estruturas:

[A] memória coletiva não se confunde com a história e a expressão "memória histórica" não é muito feliz [...]. A memória coletiva [...] é uma corrente de pensamento contínuo, de uma continuidade que nada tem de artificial [...]. A história divide a sequência dos séculos em períodos, como distribuímos a tragédia em muitos atos [...]. Ademais, existem muitas memórias coletivas. Esta é a segunda característica pela qual elas se distiguem da história. A história é só uma e se pode dizer que só existe uma história. (HALBWACHS, 2004, p. 100)

Levantado do Chão apresenta a trajetória de uma família de trabalhadores rurais alentejanos, atravessando o século XX. O romance culmina com a Revolução dos Cravos, em 1974, e acompanha a grandiosa conquista dos camponeses, que lutaram arduamente contra a exploração daqueles que constituíam a ordem vigente:

Esta terra é assim. A Lamberto Horques disse o rei, Cuidai dela e povoai-a, zelai pelos meus interesses sem vos esquecerdes dos vossos, e isto vos aconselho para conveniência minha, e se assim fizerdes sempre e bem, viveremos todos em paz. E o padre Agamedes, às ovelhas apascentadas, [...] Boas doutrinas são estas, e provavelmente por causa delas é que os quatro de Monte Lavre tiveram de aceitar que o salário ganho e não pago, nove escudos por dia, três dias e um quarto por junto na semana daquele crime, fosse para o asilo dos velhos, ainda que Felisberto Lampas tivesse resmungado quando já vinham de regresso, Se calhar, vão gastar o nosso dinheiro em cervejas. E não era verdade, desculpe-se esta juventude que tão facilmente pensa mal de quem tem mais experiência. (SARAMAGO, 2013, p. 143)

São três as instâncias de poder que fazem uso de suas ferramentas para obter um mesmo resultado: a exploração do povo. $\mathrm{O}$ autoritarismo 
dos grandes senhores é aplicado para a manutenção do Latifúndio; o discurso religioso, que incute a obediência, constitui o poder da Igreja; a polícia, como representante da ordem a serviço do Estado, age de modo a intimidar os camponeses a um passo da revolta. Por meio de tal máquina repressora, a ditadura vem a encontrar perfeitas condições para o seu estabelecimento. Para Teresa Cristina Cerdeira da Silva:

\begin{abstract}
Os ecos da história portuguesa no romance não se colam artificialmente nem são fornecidos pelo narrador como meio de criar um pano de fundo, de modo a justificar para o livro a denominação de romance histórico. Não é essa a sua perspectiva: a de criar um cenário histórico onde a ficção se pudesse desenrolar. O que parece muito mais sério é a nova maneira de ler a própria ficção como um agente recuperador da História. Não é pelo facto de os Mau-Tempos não terem um registo civil que a sua história se torna menos real. Não há que se forjar uma ambiência histórica, com um volume de informações adensado para dar historicidade ao romance, pois os homens são a História. É através da sua história que chegam ao leitor os ecos da situação portuguesa e européia, com os seus atrasos, a sua distância e as dificuldades na percepção que dos factos poderia ter um camponês alentejano, preso à terra e sem acesso à cultura e à informação. Por isso, se a História é relida em Levantado do chão, ela é-o, antes de tudo, na perspectiva do homem rural diante dos acontecimentos que compõem a história oficial. (SILVA, 1989, p. 189)
\end{abstract}

O leitor é apresentado, por um lado, à trajetória de vida e término do latifúndio, desde a Idade Média até finais dos anos 1970; por outro lado, à saga da família Mau-Tempo, que conquista seus direitos sobre a terra num processo tão grandioso quanto o das exaltadas conquistas marítimas. As duas abordagens entrelaçam-se, apresentando-nos um rico panorama das gentes portuguesas. Escolhendo uma família camponesa em particular, o narrador revela o comportamento e as representações sociais do grupo como um todo, o que se confirma em especial a partir da percepção de que "Quem diz Mau-Tempo diz outro nome qualquer" (SARAMAGO, 2013, p. 75).

Acerca de tal aspecto, Maria Alzira Seixo indica-nos que:

\begin{abstract}
Levantado do chão é, antes de mais, a epopéia dos trabalhadores alentejanos, a elucidação da reforma agrária, a narrativa dos casos, conhecidos ou não (mas quem os não conhece não terá mais desculpa para a sua ignorância, depois da publicação desta obra), que fizeram do Alentejo um mar seco de carências, privações, torturas, sangue e uma total impossibilidade de viver. [...] Romance político, pois; e sociocultural, no sentido mais pleno destes termos. Mas romance de uma nostalgia bucólica que só se não consente pelo impossível prosseguimento de uma atmosfera de brandura, romance de amores rústicos e mágicas ancestrais, romance que é um hino à natureza e um cântico da terra que deplora seus fins de tormento dos humanos, gente feita instrumento, que custa a erguerse do utensílio em que se tornou, mas que a crença no trabalho, no tempo e na vida alçam finalmente à luz redonda do dia. (SEIXO, 1999, p. 36-37)
\end{abstract}

Não obstante a narrativa atravessar diferentes regimes políticos, notam-se dois momentos cruciais para a leitura das trajetórias da família Mau-Tempo e de Portugal: o antes e o depois de 25 de Abril. No que toca à melhoria das condições de vida do operariado agrícola alentejano, o romance encena a possibilidade de o campesinato aparecer como sujeito coletivo portador de uma história própria, com base revolucionária e inflexão transformadora, capazes de insurgir contra a ordem vigente.

De acordo com as considerações apresentadas devemos ressaltar que os parâmetros do romance histórico foram delineados durante o período romântico, no início do século XIX. As marcas essenciais pautadas por Georg Lukács (2011) indicam-nos que as obras de tal gênero traçam grandes painéis sociais, abarcando determinada época e um conjunto de 
acontecimentos; a exemplo dos procedimentos típicos da escrita da história, organizam-se em observância a uma temporalidade cronológica dos acontecimentos narrados; valem-se de personagens fictícias, puramente inventadas, na análise que empreendem dos acontecimentos históricos; as personalidades, quando presentes, são apenas citadas ou integram o pano de fundo das narrativas; os dados são utilizados com o intuito de conferir veracidade à narrativa, aspecto que torna a história incontestável; o narrador se faz presente, em geral, na terceira pessoa do discurso, numa simulação de distanciamento e imparcialidade, procedimento herdado igualmente do discurso historiográfico:

\begin{abstract}
No romance histórico, portanto, não se trata do relatar contínuo dos grandes acontecimentos históricos, mas do despertar ficcional dos homens que os protagonizam. Trata-se de figurar de modo vivo as motivações sociais e humanas a partir das quais os homens pensaram, sentiram e agiram de maneira precisa, retratando como isso ocorreu na realidade histórica. E a lei da figuração ficcional - lei que em um primeiro momento parece paradoxal, mas depois se mostra bastante óbvia - que, para evidenciar as motivações sociais e humanas da ação, os acontecimentos mais corriqueiros e superficiais, as mais miúdas relações, mesmo observadas superficialmente, são mais apropriadas que os grandes dramas monumentais da história mundial. (LUKÁCS, 2011, p. 60)
\end{abstract}

O romance histórico clássico, assim, é uma narrativa baseada em um tempo anterior à época do escritor, como pano de fundo, articulando história e ficção na descrição de uma sociedade e de suas transformações. De fato, a obra estudada traça um grande painel histórico da nação portuguesa; entretanto, a subversão de algumas das propostas indicadas é notável, principalmente no que se refere ao distanciamento e à imparcialidade.

Podemos afirmar que existe um afastamento irônico que define a escrita de Saramago, tanto em termos ficcionais, quanto em termos de historiografia e de memória(s) coletiva(s). O autor demonstra que a história é o produto de um sujeito específico; o historiador recorta, seleciona, escolhe e interpreta o passado em função dos seus conceitos e valores. Em consequência, os acontecimentos não são simplesmente expostos, mas selecionados, organizados e interpretados. Essas alterações e reescrituras apontam para uma história que pode ser corrigida, problematizada e contada de um outro modo, pautando-se no descentramento do patrimônio coletivo.

O discurso historiográfico por sua vez, encontra em Saramago uma formulação própria, com o presente concebido como apropriação de um passado que o preserva, mas também o inova. Assim, com o objetivo de contribuir para o fortalecimento da identidade nacional, as diferentes gentes portuguesas são aspectos revigorados intencionalmente na ficção saramaguiana. Para Eduardo Lourenço, a inscrição do seu imaginário no passado:

[...] não é um simples capricho ou uma característica sem significado na sua ficção. Assinala-a logo como "não realista", mas de uma maneira diferente da do romance histórico para quem o "passado" devia ser evocado como presenteno Passado. A ótica de Saramago é inversa: é o Passado que é Presente. [...] A sua ficção nasce de um propósito de re-escrever uma história que já está escrita, e que como tal se vive ou é vivida enquanto "verdade" de uma época ou de um mundo, ou da humanidade quando ela é a sua ficção não inocente. (LOURENÇO, 1994, p. 186)

Nesse ponto, destacamos a importância da releitura dos fatos como memórias coletivas, patrimônios culturais armazenados pelo povo. Essa valorização ideológica das camadas populares é, indubitavelmente, legado neorrealista aproveitado por José Saramago, não somente para o desenvolvimento de Levantado do chão, mas 
também para concepção da arte que encontra nas camadas populares os elementos desencadeadores das transformações sociais.

O posicionamento de Saramago pode ser identificado, notadamente, na defesa da melhoria das condições de vida do operariado agrícola alentejano e na ênfase ao sujeito coletivo, portador de uma história própria e incentivador de uma dinâmica de profunda democratização da sociedade, os quais propiciariam uma nova movimentação, gestada por intermédio de um árduo processo de conscientização política dos trabalhadores, especialmente do campesinato lusitano:

A história das searas repete-se com variantes. Neste caso de agora, não é a andarem os homens naquele obstinado alvoroço de pedirem salário maior. A bem dizer, é a mesma ladainha todos os anos, em todas as estações e propósitos de serviço, Parece que não aprenderam a dizer outra coisa, senhor padre Agamedes, em lugar de se preocuparem com a salvação da sua reles alma imortal, se é que a têm, só cuidam dos confortos do corpo, não aprenderam a lição dos ascetas, apenas no dinheiro pensam, nem perguntam se o há e a mim me convém pagar. (SARAMAGO, 2013, p. 400)

Tendo em vista os tensionamentos que abarcam literatura e história, o processo narrativo em Levantado do chão focaliza as camadas silenciadas. A grandiosidade portuguesa é construída também (e principalmente) por aqueles que não estão inscritos na galeria dos herois:

[...] crucifica-te, estende o braço para a sangria, abre as veias e diz, Este é o meu sangue, bebei, esta é a minha carne, comei, esta é a minha vida, tomai-a, com a bênção da igreja, a continência à bandeira, o desfile das tropas, a entrega das credenciais, o diploma da universidade, façam-se em mim as vossas vontades, assim na terra como nos céus. (SARAMAGO, 2013, p. 74)

As passagens iniciais da obra aparesentam- nos a Domingos Mau-Tempo e sua esposa, Sara da Conceição. Domingos é um sapateiro briguento e alcoólatra, incapaz de se estabelecer nos sítios que habita. Sua natureza errante acarreta grandes sofrimentos para toda a família - é pai de cinco crianças, dentre as quais se destaca João Mau-Tempo, cujas peripécias o narrador seguirá, assim como a dos seus filhos, Amélia, Gracinda e António Mau-Tempo. Maria Adelaide, filha de Gracinda Mau-Tempo e de António Espada, é a personagem com a qual se concluirá a narração, com a derrocada de um do regime ditatorial, em Abril de 1974. Apesar do emblemático nome, o narrador fornece pistas de que é preciso ter esperanças em um futuro melhor, pois "esta família Mau-Tempo parece escolhida pelo destino para negros casos, mas seria fruto de pouco entendimento assim supor" (SARAMAGO, 2013, p. 65).

Se a historiografia elegeu o ponto de vista dos senhores de terras, do Estado e da Igreja, chegou o momento de dar preenchimento ao vazio e reconstruir os fatos pelos olhos da família MauTempo - em especial os olhos azuis, herdados de um antigo forasteiro, Lamberto Horques, que havia alguns séculos, violara uma moça da região:

\footnotetext{
Minha querida filha, e é então que João MauTempo vê que os seus olhos são imortais, estão ali depois de uma longa peregrinação, nem ele conhece o mais distante dela, donde vem, como foi, basta-lhe que em Monte Lavre outros assim não houvesse, tanto na sua família como fora dela, os filhos da minha filha meus netos são, os do meu filho serão ou não, ninguém se livra de malícias populares, mas destes ninguém pode duvidar, olhem bem para mim, para estes meus olhos azuis, e agora vejam os desta minha neta, que vai chamar-se Maria Adelaide e é retrato daquela sua avó com mais de quinhentos anos, mais os olhos que são do seu avô salteador estrangeiro de donzelas. Todas as famílias tem as suas fábulas, algumas nem isso sabem, como esta dos Mau-Tempos, que bem a podem agradecer ao narrador. (SARAMAGO, 2013, p. 297-298)
} 
A permanência secular dos olhos azuis na família Mau-Tempo representa a marca da exploração histórica sofrida, que não pode ser esquecida ou apagada, a primeira e mais antiga a que foi submetido o povo alentejano, subjugado dia após dia por seus senhores. Essa marca, posteriormente, servirá para a grande tomada de consciência: saber quem realmente são e, ao levantarem-se do chão, lutar por seus direitos e por um espaço que lhes pertença.

O contraste social riqueza/pobreza marca as representações do latifúndio, espaço em que a fartura dos campos opõe-se à miséria daqueles que os mantêm:

O que mais há nessa terra, é paisagem. Por muito que do resto lhe falte, a paisagem sempre sobrou, abundância que só por milagre infatigável se explica, porquanto a paisagem é sem dúvida anterior ao homem, e apesar disso, de tanto existir, não se acabou ainda. Será porque constantemente muda: tem épocas no ano em que o chão é verde, outras amarelo, e depois castanho, ou negro. E também vermelho, em lugares que é cor de barro ou sangue-sangrado. Mas isso depende do que no chão se plantou e cultiva, ou ainda não, ou não já, ou do que por simples natureza nasceu, sem mão de gente, e só vem a morrer porque chegou seu último fim. (SARAMAGO, 2013, p. 11)

Trata-se de um lugar em que as esperanças de muitos se esvaem, assim como suas forças para lutarem por uma vida mais digna. As leis são ditadas pela cobiça, pelo poder e pelos interesses de poucos:

O dinheiro sobe, só para subir tem asas, não para descer. O lugar do dinheiro é um céu, um alto lugar onde os santos mudam de nome quando vem a ter de ser, mas o latifúndio não. Madre de tetas grossas, para grandes e ávidas bocas, matriz, terra dividida do maior para o grande, ou mais de gosto ajuntada do grande para o maior, por compra dizemos ou aliança, ou de roubo esperto, ou crime estreme, herança dos avós e meu bom pai, em glória estejam. Levou séculos para chegar a isto, quem duvidará de que assim vai ficar até à consumação dos séculos? E esta outra gente quem é, solta e miúda, que veio com a terra, embora não registada na escritura, almas mortas, ou ainda vivas? A sabedoria de Deus, amados filhos, é infinita: aí está a terra e quem a há-de trabalhar, crescei e multiplicaivos. Crescei e multiplicai-me, diz o latifúndio. Mas tudo isso pode ser contado de outra maneira. (SARAMAGO, 2013, p. 13)

Ao afirmar já nas páginas iniciais da obra que tudo pode ser contado de outra maneira, o narrador assume que são muitas as possibilidades de perceber e relatar um mesmo fato, o que solicita do leitor uma percepção mais crítica tanto da historiografia quanto do (seu) fazer literário.

As conquistas dos trabalhadores são apresentadas como uma consequência da organização popular, baseada na crença marxista de que as mudanças decorrem da conscientização. Inicialmente, nesse processo, temos João MauTempo, filho mais velho de Domingos MauTempo e de Sara Conceição que "um dia, moído de pancada e de trabalho excessivo, desafiou a ameaça de ser esfolado e desossado, e abriu-se com a mãe estupefata" (SARAMAGO, 2013, p. 55). A insatisfação com sua condição é cada vez maior, levando-o a reflexões sobre a exploração: “tu és um homem, és o parceiro enganado de uma grande batota universal, brinca, que mais queres, o salário não dá para comer" (SARAMAGO, 2013, p. 76).

O questionamento da sua situação e a corajosa verbalização demonstram a passagem para um degrau superior de consciencialização social. Todavia, não há aqui ainda luta coletiva organizada. O atingir de um novo patamar virá com o término da Segunda Guerra Mundial. É nesse período que uma onda popular de reivindicação pela democratização percorre o país. Também é nesse momento que o Partido Comunista Português se torna a força política hegemônica nos campos alentejanos. 
A aplicação de maquinaria à produção agrícola resultaria, nas condições do capitalismo tardio, na expulsão de operários do trabalho agrícola, o que eleva a taxa de desemprego nos campos e torna a imposição de ritmos de trabalho desumanos:

Vai o moço para a moinha, recebe-a na cara como um castigo, e o corpo começa de mansinho a protestar, para não mais lhe sobram as forças, mas depois, só não o sabe quem isto não tenha vivido, o desespero alimenta-se da extenuação do corpo, torna-se forte e a sua força regressa violenta ao corpo, e então, de dois feitos, o rapaz, que se chama Manuel Espada, deixa a moinha, chama os companheiros e diz, Vou-me embora, que isto não é trabalhar, é morrer. (SARAMAGO, 2013, p. 104)

Temos aqui um princípio de greve, iniciada pelas próprias impossibilidades físicas dos trabalhadores. As consequências não demoram a surgir:

[...] no domingo foram os quatro grevistas à praça e não arranjaram patrão. E no outro, e no outro também. O latifúndio tem boa memória e fácil comunicação, nada lhe escapa, vai passando palavra, e só quando muito bem lhe parecer dará o feito por perdoado, mas esquecido nunca. (SARAMAGO, 2013, p. 109)

Diante do quadro, os trabalhadores, "encontram-se aos três e aos quatro em sítios escondidos, e mantêm grandes conversações. Fala sempre um de cada vez e todos os mais ouvem" (SARAMAGO, 2013, p. 121). A existência de lideranças políticas revolucionárias e ligadas aos interesses dos trabalhadores, bem como o caráter coletivo e a ruptura com a inércia e o conformismo contribuem para que os grevistas se percebam como classe, com interesses assumidamente tomados como distintos e opostos aos das classes dominantes. Paralelamente, a burguesia, os capatazes e os guardas respondem com o aumento da exploração e o aumento da repressão.

Tal reação, a longo prazo, tem como resposta o fortalecimento da unidade dos alentejanos e permite que estes identifiquem mais claramente quem são os seus antagonistas, bem como de onde vem a causa da condição exploratória:

\begin{abstract}
Camaradas, não se deixem enganar, é preciso que haja união entre os trabalhadores, não queremos ser explorados, aquilo que pedimos nem sequer chegava para encher a cova dum dente ao patrão. E avança o Manuel Espada, Nós não podemos ser menos que os camaradas das outras terras, que a esta hora reclamam um salário mais certo. E há um Carlos, outro Manuel, um Afonso, um Damião, um custódio, e um Diogo, e também um Filipe, todos a dizerem o mesmo, a repetir as palavras que acabaram de ouvir, só a repeti-las porque ainda não tiveram tempo de inventar outras suas próprias, e agora adianta-se João Mau-Tempo, (...) juntemonos todos para exigir o nosso salário, porque já vai sendo tempo de termos voz para dizer o valor do trabalho que fazemos, não podem ser sempre os patrões a resolver o que nos pagam. (SARAMAGO, 2013, p. 144)
\end{abstract}

A evolução da luta organizada, a partir da união dos trabalhadores, é representada como o maior receio da classe dominante, conforme nos indica o diálogo entre o pároco e a esposa de um latifundiário: "o orgulho é um pecado mortal, $\mathrm{O}$ pior de todos, senhora dona Clemência, porque é ele que levanta o homem contra o seu patrão e o seu deus" (SARAMAGO, 2013, p. 245).

A compreensão de que a luta faz parte de um longo processo é um ponto também evidenciado na obra:

[...] a Montemor vamos segunda-feira, reclamar o pão dos filhos e dos pais que os devem criar, Mas isso é o que sempre fizemos, e os resultados, Fizemos, fazemos e faremos, enquanto não puder ser diferente, Canseira que não acaba nunca, Um dia acabará, Quando já estivermos todos mortos e ao de cima vierem os nossos ossos, se houver cães 
que os desenterrem, Vivos haverá bastantes quando chegar esse dia. (SARAMAGO, 2013, p. 308)

Assim, a coragem em afrontar um inimigo com recursos financeiros, políticos, militares e ideológicos muito superiores é uma prova do avanço progressivo da capacidade de organização e persistência do proletariado alentejano. Com a Revolução dos Cravos, chega, enfim, a liberdade de manifestação; os trabalhadores finalmente consumam as suas aspirações pela lida por si mesmos, sem necessidade de abusos:

E então num sítio qualquer do latifúndio, a história lembrar-se-á de dizer qual, os trabalhadores ocuparam uma terra. Para terem trabalho, nada mais, cubra-se de lepra a minha mão direita se não é verdade. E depois numa outra herdade os trabalhadores entraram e disseram, Vimos trabalhar. E isto que aconteceu aqui, aconteceu além, é como na Primavera, abre-se um malmequer do campo, e se não vai logo Maria Adelaide colhê-lo, milhares de seus iguais nascem em um dia só, onde estará o primeiro, todos brancos e todos voltados ao sol, é assim o noivado desta terra. (SARAMAGO, 2013, p. 361)

A luta organizada, correlativa da elevação dos níveis de reflexão dos trabalhadores, aparece como o fator de maior impacto para a transformação social. O enfoque não é mais a ação individual, tradicionalmente apresentada pela literatura portuguesa, mas a coletiva, a partir da qual os trabalhadores adquirem clareza sobre sua situação na sociedade e confirmam-se como classe consciente dos interesses econômicos, políticos e ideológico-culturais que movem os grupos sociais hegemônicos.

Pode-se afirmar, ainda, que os aspectos neorrealistas do romance são fundamentais à ressignificação de acontecimentos passados sob o ponto de vista do subalterno. As imbricações de episódios públicos e privados de uma família problematizam a responsabilidade dos homens diante dos impasses dos acontecimentos históricos, o que nos possibilita buscar, em suas lacunas, o pretexto para revisitá-los e tecer críticas a respeito de tais omissões.

Considerar as dificuldades daqueles que, no campo, produzem e fornecem a mão de obra para sustentar os que estão no poder reforçam o fato de que Saramago olha para o latifúndio, mar de terra, como o novo espaço das viagens épicas e da saga de muitos portugueses, sem nomes nobres. Sendo assim, a reescrita do passado, sob uma voz narrativa de características neorrealistas, que questiona o legado político de outrora, confere a reavaliação ideológica dos fatos e dos atores sociais, por certo um sentido alternativo que privilegia o marginalizado e redimensiona o papel revolucionário da escrita conscientizadora de Saramago.

\section{Referências}

HALBWACHS, M. A memória coletiva. Trad. Laís Teles Benoir. São Paulo: Centauro, 2004.

JUNIOR, B. A. \& PASCHOALIN, M. A. História Social da Literatura Portuguesa. São Paulo: Ática, 1985.

LOURENÇO, E. O canto do signo. Existência e literatura (1957-1993). Lisboa: Presença, 1994.

LUKÁCS, G. O romance histórico. Trad. Rubens Enderle. São Paulo: Boitempo, 2011.

SARAMAGO, J. Levantado do chão. São Paulo: Companhia das Letras, 2013.

SEIXO, M. A. Lugares da ficção em José Saramago. Lisboa: INCM, 1999

SILVA, T. C. C. José Saramago entre a história e a ficção: uma saga de portugueses. Lisboa: Dom Quixote, 1989.

VIÇOSO, V. "Levantado do chão e o romance 
neo-realista". In: Colóquio Letras: 1999, n. $151 / 152$, p. 239-248.

Artigo enviado em: 25/10/2016

Aceite em: 14/07/2016 